\title{
Decisive Is What the Tattoo Shows: Differences in Criminal Behavior Between Tattooed and Non-tattooed People
}

\author{
Nina Zeiler, Erich Kasten \\ Medical School Hamburg, University of Applied Sciences, Am Kaiserkai, Hamburg, Germany \\ Email address: \\ nina.zeiler@outlook.de (N. Zeiler), erikasten@aol.com (E. Kasten)
}

\section{To cite this article:}

Nina Zeiler, Erich Kasten. Decisive Is What the Tattoo Shows: Differences in Criminal Behavior Between Tattooed and Non-tattooed People. Social Sciences. Vol. 5, No. 2, 2016, pp. 16-20. doi: 10.11648/j.ss.20160502.12

Received: February 14, 2016; Accepted: February 28, 2016; Published: March 29, 2016

\begin{abstract}
Background: Many people have prejudices that subjects with tattoos have a tendency to criminal behavior. This article deals with the question if there really are differences in the inclination to criminal behavior between tattooed and nontattooed people. Method: The investigation was conducted using 15 short descriptions of criminal behavior, which represent different crimes i.e. theft, burglary, malicious damage, consuming drugs, drinking alcohol in public transport or acting violent. The participants had to rate from zero to ten how they would react in these situations. A total of 110 persons (average age 23.5 y., $66.4 \%$ male, $33.6 \%$ female; $55 \%$ no tattoo, $45 \%$ tattooed) were interviewed. Results: There was a small but significant difference between tattooed and non-tattooed people. Interestingly there was a significant intra-group difference between more pacific and more aggressive tattoo themes. In consideration of the gender, the number of tattoos and the visibility of tattoo no significant differences or correlations were discovered. Conclusion: Decisive for the tendency toward criminal behavior is not, whether someone has a tattoo or not; more important is what the tattoo shows. Apparently people with aggressive tattoos are more prone to criminal behavior, but not people with peaceful tattoos.
\end{abstract}

Keywords: Tattoo, Criminal Behavior, Prejudices

\section{Introduction}

Body Modifications, especially tattoos, are millennium of years old. A mummy from Chile with signs in the skin has been dated back to 7,000 BC. Since ancient times, peoples with tattoos are spread all over the world, especially in countries with warm temperatures [5]. Beginning in the $15^{\text {th }}$ century, the Europeans travelled in foreign continents. In a lot of countries in the equatorial region they discovered different types of tattoos and other kinds of body modifications. When they came back to Europe they brought the tattoos with them. At first the tattoos of the sailors were an expression of pilgrimages. Later the society changed their point of view about tattoos: The upper and middle class of the society were against tattoos in contrast to the lower class. In those times the criminologists searched for a connection between crimes and tattoos [13]. But what is the meaning of tattoos nowadays and is there really a connection between tattoos and crime? According to Wohlrab, Stahl \& Kappeler [18] tattoos are an expression of protest and a provocation towards parents, teachers and the remnant of the society. But individuality and otherness are not the only values represented by tattoos. Often people use their tattoo to express their belonging to a special group, expressing a new sense of life [6].

People meet, notice, judge and categorize others every day and most people make rapid conclusions without knowing something about the others. Thinking in such categories is the reason for prejudices. In turn these expectations of the behavior of other people are the reason for their reactions. In the context of tattoos exist such prejudges about a connection between tattoos and criminal behavior patterns. Ago in 1908 the prosecution attorney E. Wulffen [19] wrote in his book "Criminal-Psychology" about his own prejudices in regard to tattoos. He took the view that people, who offered their naked body to the tattooist to "deform" their skin in such a fixed way, exhibit an insensibility of their emotional personality, which also was typical for criminals. In his opinion "noticeable tattoos were an indication for inferiority of ethic feelings and the intellect" (p. 258 [19]). Today, despite strong spreading of tattoos in the Western World of 
the 21 st century, some of these prejudices are still common. The main question of this study is, whether these prejudices conform to real criminal behavior?

On this basis, this article deals with the question if there are differences of criminal behavior between tattooed and non-tattooed individuals. Due to the wide spread of tattoos, it is not surprising that even many criminals have pictures in their skin [15]; on the other hand there is no real evidence for a connection between having a tattoo and getting to be a criminal. Historical studies in the $19^{\text {th }}$ century, e.g. from Lombroso and Ferreror [10] showed a considerable frequency of tattooed people in jail. To understand the idea, why tattooed people might be more criminal, it is important to have a look at the history. The first individuals, who wore tattoos in Europe, were sailors. After long times on the high seas, they received their wages for months of work, then beat ashore over the traces and often ended in prison. Later the motorcycle-driving rockers were proud to show their tattoos on muscular upper arms.

Theories of crime try to find out the reasons for acting in a criminal way distinguish e.g. between individual causes like the genetic based personality [11] or learning behavior during the development (i.e. Sutherland \& Cressey [16]; Förtig [3]); but even the social structure of the society can support criminal behavior [14] (e.g. the labeling approach of Lemert [8]). These explanations about the development in combination with the circumstances about getting a tattoo and the prejudices about them lead to this study.

In 2002 Deschesnes, Finès \& Demers [2] performed a study at a Canadian High School. They examined any links between a number of risk-taking behaviors and having tattoos or piercings. Overall they interviewed about 2,180 pupils (aged between 12 and 18 y.) in 23 different High Schools. Data were collected directly in a self-report survey. The results suggested links between being tattooed or pierced and different illegal activities, gang affiliation, problem gambling, school truancy, as well as attendance at rave events.

A study done by Guéguen [4] in 2012 interviewed young men and women after they had left a pub in France. The authors ascertained data about wearing a tattoo or piercing and the level of alcohol consumption. The result of this study showed that tattooed people had a higher level of alcohol consumption than the non-tattooed participants. The same conclusion pertains for the people who had a piercing.

In 2013 King and Vidourek [7] performed a study in a University in Cincinnati, US, to examine associations between wearing a tattoo and tendencies for risky behaviors. 998 students took part in this investigation. $29.6 \%$ of them had a tattoo; more females than males. Tattooed students were significantly more likely than non-tattooed students to take part in alcohol and marijuana use and risky sexual behaviors. On the other hand, suicidal behaviors as well as suicidal ideation were not related to having a tattoo.

In 2014 a study by Liao, Chang \& Su [9] questioned young Chinese detainees in a jail in Taiwan. As a result of this study prisoners with tattoos were more willing to commit fraud, drug consumption, homicide and murder than detainees without tattoos.

In relation to the prejudices about tattooed people a study done by Cebula and Kasten [1] in 2015 interviewed 100 students to find out more about connections between being tattooed and intelligence and creativity. To collect data, an intelligence questionnaire was used and one test to measure creativity. Moreover the students had to answer questions about having tattoos or not. There were no significant group differences relating to intelligence as well as no correlation between being tattooed and the level of creativity.

In 2015 Swami et al. [17] investigated the stereotype, whether people with tattoos are more aggressive and rebellious than people without tattoos. The authors asked 378 adults in London, UK, to complete self-report measures of aggression and rebelliousness, and to report the number of tattoos they possessed. Of this sample, $25.7 \%$ possessed at least one tattoo. Swami and co-authors found that tattooed adults had significantly higher reactive rebelliousness, anger, and verbal aggression than non-tattooed adults. However, effect sizes were small and there were no significant between-group differences in terms of proactive rebelliousness, physical aggression, and hostility. These results suggest that, while stereotypes may contain a kernel of truth, they likely present an outmoded picture of tattooed adults.

Based on the results of these studies the here presented investigation was performed to examine whether there is really a difference between tattooed/non-tattooed people and the inclination to criminal behavior patterns. The 1 . hypothesis assumes that there is no difference in criminal behavior patterns between tattooed and non-tattooed people. The 2. hypothesis supposes that the criminal behavior of men and women is similar. The 3. hypothesis starts from the premise that the criminal behavior is independent of the number of tattoos. The 4 . hypothesis presumes that the criminal behavior is equal in people with friendly tattoo motives and people with aggressive tattoo motives. And the 5. hypothesis expects no difference between people with visible tattoos and people with invisible tattoos.

\section{Methods}

\subsection{Participants}

This study was intended to investigate differences between tattooed and non-tattooed people. For that reason the sample included participants with tattoos as well as participants without tattoos. To achieve a homogenous sample without large differences of intelligence and the level of education, all participants were students. Overall 110 participants were interviewed.

\subsection{Questionnaire}

A self-constructed questionnaire was used to collect the data. It consists of two parts: The first part contains general information about the study, i.e. topic of the study, 
confidentiality of the information and anonymity of the data, to inform the participants before they take part in the survey. Demographic data like gender and age were collected. In addition, the first part inquires whether the participants have a tattoo or not. If they have one, they were asked to give detailed information like number of tattoos, motives and position on the body. The second part included fifteen short descriptions of criminal behavior. This part represented different crimes i.e. theft, burglary, malicious damage, consuming drugs, drinking alcohol in public transport or acting violent. The participants had to rate from zero to ten how they would react in these situations. Zero means "I would never do this"; ten means "I would do this for sure". By rating, the participants only have to state a potential probability. The processing time was about 10 minutes by using a paper pencil process.

Items were:

1. Crossing at night a red traffic light.

2. A found wallet with 50,- Euro not give to the lost property office.

3. Using a public train without a ticket.

4. Take home a bathrobe from a hotel.

5. Picking an apple on a field.

6. Take some rolls of toilet paper from a public toilet.

7. Drinking alcohol in public transport.

8. Steal a bicycle.

9. Break a cigarette-machine.

10. Scratch a car that constantly blocks the way.

11. Steal something in a mall without paying.

12. Break a kiosk to get some money.

13. Consume drugs at a party, offered for free.

14. Driving without driver's license with a borrowed car.

15. Use physical violence against others.

\section{Results}

\subsection{Sample}

110 participants, aged between 19 and 46, took part in the survey. On an average the participants were 23.57 (SD = 4.12) years old. $73(66.4 \%)$ participants were female and 37 $(33.6 \%)$ were male. From the total sample, 60 people had no tattoo and 50 people had at least one tattoo. The following table shows the distribution of the gender as well as the distribution of the gender in relation to having a tattoo or not.

Table 1. Distribution of gender and tattoos.

\begin{tabular}{lllll}
\hline & Female (N) & Male (N) & Female (\%) & Male (\%) \\
\hline Tattooed & 34 & 16 & 30.9 & 14.5 \\
Non-tattooed & 39 & 21 & 35.5 & 19.1 \\
Total & 73 & 37 & 66.4 & 33.6 \\
\hline
\end{tabular}

One participant had a maximum of 11 tattoos, in average the participants had 2.64 tattoos. To get an overview about the different types of motives of the tattoos, they were categorized.

Animal tattoos: Lion $(2 x)$, eagle $(2 x)$, bird $(2 x)$, butterfly $(2 x)$, swallow (2), dragon $(2 x)$, snake $(2 x)$, deer $(1 x)$, owl (1x), elephant $(1 x)$, gecko $(1 x)$, phoenix (1x), panda $(1 x)$, crab (1x), wolf (1x), pit bull (1x).

Symbols: Heart $(8 x)$, anchor $(5 x)$, star $(3 x)$, tree $(2 x)$, ring $(1 x)$, circle $(1 x)$, lawnmower $(1 x)$, queen of hearts $(1 x)$, ribbon $(1 \mathrm{x})$, feather $(1 \mathrm{x})$, celtic knot $(1 \mathrm{x})$, celtic cross $(1 \mathrm{x})$, memory of a person (1x), ocean (1x), US-state (1x).

Names: Names $(2 x)$, initials $(1 x)$, own name $(1 x)$, parent's names $(1 \mathrm{x})$, grandma's name $(1 \mathrm{x})$.

Signs: Signs $(3 x)$, letters $(1 x)$, lettering $(1 x)$, tribal $(1 x)$.

Religious: Angel $(2 \mathrm{x})$, angel's wings $(1 \mathrm{x})$, cemetery $(1 \mathrm{x})$, Bible verse (1x).

Fabulous: Mermaid (1x), pixie (1x).

Music: Music knot (1x), guitar (1x).

Flowers: Flowers $(6 x)$, roses $(2 x)$.

People: Woman (2x), Maori (1x), geisha (1x).

Strokes: Strokes $(11 \mathrm{x})$.

Others: Skeleton $(2 \mathrm{x})$, calavera $(1 \mathrm{x})$, claddagh $(1 \mathrm{x})$, bomb $(1 x)$, gavel (1x), sword (1x), skull (1x).

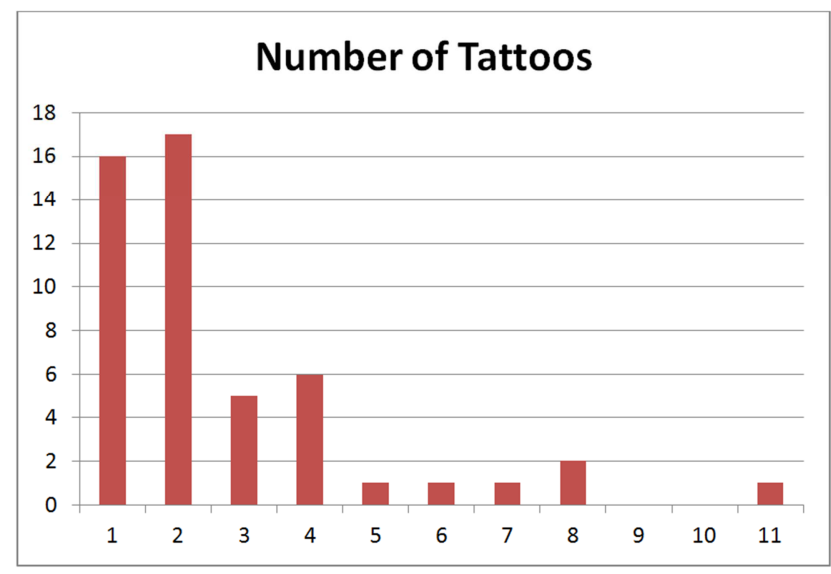

Figure 1. Distribution of frequency per number of tattoos.

Table 2. Positions of the tattoos - divided into visible and invisible positions $(n=45)$.

\begin{tabular}{ll}
\hline Visible $(\mathbf{n}=\mathbf{1 2})$ & Number \\
\hline Arms & 12 \\
Wrist & 7 \\
Upper arms & 7 \\
Lower arms & 6 \\
Collarbone & 4 \\
Finger & 1 \\
Invisible(n=33) & Number \\
Ribs & 15 \\
Back & 13 \\
Foot & 9 \\
Leg & 6 \\
Shoulder & 5 \\
Calf & 4 \\
Nape & 4 \\
Chest & 3 \\
Stomach & 3 \\
Waist & 2 \\
Ledge & 2 \\
Behind the ear & 1 \\
Hips & 1 \\
Backside & 1 \\
Ankle & 2 \\
\hline
\end{tabular}


In addition, the positions on the bodies were divided into visible and invisible locations (see Table 2.) The category 'visible' includes those parts of the body which were also visible if the participants wore a t-shirt and long trousers. In comparison to this the category 'invisible' includes the rest of the body. Behind the ear and nape were also invisible because the participants who have tattoos on these positions were women. The authors supposed long hairs which overlay these positions.

\subsection{Detailed Results}

All results were reckoned with IBM SPSS Statistics 23. As described above, the main hypothesis was to investigate the difference between two groups (tattooed and non-tattooed) in regard to criminal intentions. Data of the questionnaire were on an ordinal level; therefore the non-parametric MannWhitney U-Test for independent groups was performed. The U-test was tested on an $\alpha$-level of $\mathrm{p}<0.05$. For this hypothesis SPSS calculated a value of $p=0.025$, which means the U-test $(\mathrm{U}(50,60)=110, \quad p \leq 0,05)$ shows a significant difference between the two groups. Therefore the alternative hypothesis, tattooed have a stronger inclination to criminal behavior patterns than non-tattooed people, was accepted.

The 2. hypothesis was about a difference between men and women. SPSS reckoned a value of $p=0.086$. $(\mathrm{U}(50,60)=110$, $p \geq 0.05$ ), i.e. there is no significant difference between the genders. The null hypothesis, that men and women have the same inclination to criminal behavior patterns was retained.

The 3. hypothesis refers to the number of tattoos. The Spearman's rank correlation shows no significant result $\left(r_{s}\right.$ $(110)=.149, p>.001)$, , i.e. no significant correlation exists between the number of tattoos and the criminal behavior score.

The 4. hypothesis based on the categories friendly/aggressive tattoos. With a value of $p=0.003$. $(\mathrm{U}(50,60)=110, p \leq 0.05)$ the U-test shows a significant difference between participants with friendly tattoos motives and participants with aggressive tattoo motives regarding their inclination to criminal behavior.

The last hypothesis focused on the visibility of the tattoos. The value of the U-test of $p=0.205$ is considerable higher than 0.05 , which means that there is no significant difference. The hypothesis that there is no difference between people whose tattoos are visible and people whose tattoos are invisible in regard to their criminal behavior, was maintained.

\section{Discussion}

Until now, there are only a few investigations in the specific domain of crime and tattoos. Other studies, i.e. the above mentioned studies of Deschesnes, Finès \& Demers [2], Guéguen [4], or Roberts \& Ryan [12] focused on occurred criminal behavior. In contrast to these studies the current study collected only data about the inclination to criminal behavior.

To have homogenous groups, in this study only students have been interviewed, which, on the other hand, limits the generalizability of the results to the total population. The detailed results of the study show that there is not only a difference between tattooed and non-tattooed people but rather decisive is what the tattoo shows. There is a significant difference between the groups with more peaceful and more aggressive tattoos. For people with tattoos these results mean that the prejudices against them may not be only build of the fact that they have tattoos, but rather what their tattoo shows. Especially, concerning the criminal behavior potential, the people whose tattoo motives are more aggressive have to struggle with stronger prejudges. Due to the result of this study that they really tend to be more criminal some people could feel vindicated in their prejudices.

\section{Conclusion}

The findings of this study suggest the need for more enlightenment of the meanings of tattoos. There is a huge variability of motives for having a tattoo; but much larger are the different personalities of the individuals who wear a tattoo. The picture of the tattoo always allows partial insight into her or his personality. In spite of the fact that in this study a difference in the inclination of criminal behavior patterns between tattooed people and non-tattooed people was found, this could not justify prejudices against all tattooed people. There is obviously a difference which image on the tattoo the carrier chooses. The here made subdivision in peaceful and aggressive tattoos is still very rough. In the form of qualitative interviews, future research should focus on the individual reasons for different kinds of tattoos. This might include more sociodemographic data as well as a look on the social environment and development of the participants. Last not least, in assessing the skills and virtues of the tattoo-carrier one should not be impressed only by the kind of body-modifications, or, as we psychologists say: You have to look deeper than on the skin.

\section{Acknowledgements}

The authors thank all participants of this study.

\section{References}

[1] Cebula, A. S. \& Kasten, E. (2015). Differences in Intelligence and Creativity between Tattooed and Non-Tattooed Students. Psychology and Behavioral Sciences, 4 (4), 165-169. doi: 10.11648/j.pbs.20150404.14.

[2] Deschesnes, M., Finès, P. \& Demers, S. (2006). Are tattooing and body piercing indicators of risk-taking behaviours among high school students? Journal of Adolescence, 29, 379-393. doi: 10.1016/j.adolescence.2005.06.001.

[3] Förtig, H. (2002). Jugendbanden. [Youth gangs]. München: Herbert Utz Verlag GmbH.

[4] Guéguen, N. (2012). Tattoos, Piercings, and Alcohol Consumption. ISBRA, 36(7), 1253-1256. doi: 10.1111/j.15300277.2011.01711.x. 
[5] Junker, H. (2008). Aussagemöglichkeiten zu Tätowierungen aus vor- und frühgeschichtlicher Zeit. [Expressive possibilities to tattoos from prehistoric and early historical times.] Unpublished Magister-Thesis, University of Hamburg, Germany.

[6] Kasten, E. (2006). Body Modification. München, Basel: Reinhardt.

[7] King, K. A. \& Vidourek R. A. (2013). Getting inked: Tattoo and risky behavioral involvement among university students. The Social Science Journal, 50, 540-546.

[8] Lemert, E. M. (1951). Social pathology: A systematic approach to the theory of sociopathic behavior. New York: McGraw-Hill.

[9] Liao, P., Chang, H. \& Su, Y. (2014). Is tattooing a risk factor for adolescents' criminal behavior? Empirical evidence from an administrative data set of juvenile detainees in Taiwan. Society for Risk Analysis, 34, 2080-2088. doi: 10.1111/risa.12232.

[10] Lombroso, C \& Ferrero, G. (1894). Das Weib als Verbrecherin und Prostituierte. [Woman as criminal and prostitute] Hamburg: Verlagsanstalt A.-G., Königlich schwedischnorwegische Hofverlagshandlung.

[11] Mergen, A. (1968). Der geborene Verbrecher - Ein Bericht über Chromosomenforschung und Kriminologie. [Born criminals - A report on chromosome research and criminology]. Hamburg: Kriminalistik Verlag.

[12] Roberts, T. \& Ryan, S. (2002). Tattooing and High-Risk Behavior in Adolescents. Pediatrics, 110, 1058-1063.
[13] Schüttpelz, E. (2006): Unter die Haut der Globalisierung. Die Veränderungen der Körpertechnik 'Tätowieren' seit 1769. [Under the skin of globalization. The changes in body art 'tattooing' since 1769th] In: Nanz, T. \& Siegert, B. (Eds): Ex machina. Kulturtechniken und Medien. Medien/i, Band 19. Weimar: VDG, 109-154.

[14] Schwind, H.-D. (2011). Kriminologie. [Criminology]. Heidelberg: Kriminalistik Verlag.

[15] Stöver, H. \& Bammann, K. (2006). Tätowierungen im Strafvollzug: Haft-Erfahrungen, die unter die Haut gehen. [Tattoos in prison: prison experiences that get under your skin]. Oldenburg: BIS-Verlag der Carl von Ossietzky Universität Oldenburg.

[16] Sutherland, E. H., \& Cressey, D. R. (1984). Differential association theory. In D. H. Kelly (Ed.), Deviant behavior (2nd ed.). NY: St. Martins Press, 125-131.

[17] Swami, V., Gaughan. H., Tran, U. S., Kuhlmann, T., Stieger, S. \& Voracek, M. (2015). Are tattooed adults really more aggressive and rebellious than those without tattoos? Body Image, 15, 149-152. doi: 10.1016/j.bodyim.2015.09.001.

[18] Wohlrab, S., Stahl, J. \& Kappeler, P. M. (2007). Modifying the body: Motivations for getting tattoed and pierced, Body Image, 4, 87-95. doi: 10.1016/j.bodyim.2006.12.001.

[19] Wulffen, E. (1908): Psychologie des Verbrechers. [Psychology of the criminal]. In: Enzyklopädie der modernen Kriminalistik, Bd. I. Berlin, Langenscheidt-Verlag, 258-259. 